\title{
Analysis of Urban Atmosphere Plume Concentration Fluctuations
}

\author{
Dennis Finn • Kirk L. Clawson • Roger G. Carter • \\ Jason D. Rich · Chris Biltoft • Martin Leach
}

Received: 4 November 2009 / Accepted: 18 May 2010 / Published online: 4 June 2010

(C) The Author(s) 2010. This article is published with open access at Springerlink.com

\begin{abstract}
Concentration variability in the fast-response tracer dataset for continuous, near-surface, point source releases in the urban core from the Joint Urban 2003 field study is analyzed. Concentration variability for conditionally and unconditionally sampled time series is characterized by probability densities, concentration fluctuation intensity, skewness, and kurtosis. Significant day-night differences in plume dispersion are observed. Relative to daytime, nighttime plumes were more likely to have reduced concentration fluctuation intensities, higher normalized surface concentrations, suppressed vertical mixing, and a greater prevalence of Gaussian-like distributions rather than log-normal or mixed mode distributions. This was in spite of the similar stability and turbulence conditions in the urban core for day and night. The potential roles of flow meander and thermal stability in explaining these differences are examined. Probability densities of concentration are found to be a strong function of fluctuation intensity. There are few differences in probability densities between day and night when classified by fluctuation intensity. There are no appreciable differences between conditional and unconditional probability densities and only small differences between conditional and unconditional sampling statistics relative to the larger differences usually observed in more homogeneous settings. Fluctuation intensity, skewness, and kurtosis are higher for the daytime experiments, and closer to the source, but show little difference between conditional and unconditional results over most of their range of values. The log-normal
\end{abstract}

Sponsorship: This work was supported by the National Oceanic and Atmospheric Administration, by the U.S. Dept. of Homeland Security, and under contract MIPR3ADPG87013 by the Defense Threat Reduction Agency.

D. Finn $(\varangle) \cdot$ K. L. Clawson · R. G. Carter · J. D. Rich

National Oceanic and Atmospheric Administration, Air Resources Laboratory, Field Research Division, 1750 Foote Drive, Idaho Falls, ID 83402, USA

e-mail: dennis.finn@noaa.gov

C. Biltoft

Adiabat Meteorological Services, Salt Lake City, UT, USA

M. Leach

Department of Meteorology, San Jose State University, San Jose, CA, USA 
distribution provides a better overall fit to a broader range of the dataset than the exponential or clipped-normal distributions.

Keywords Day-night differences · Fluctuation intensity · Probability densities · Toxic dosement · Urban plume dispersion

\section{Introduction}

Joint Urban 2003 (JU03) was a comprehensive field campaign designed to study the transport and diffusion of pollutants in an urban boundary layer. It was a collaborative effort involving the U.S. Department of Homeland Security (DHS), U.S. Department of Defense-Defense Threat Reduction Agency (DTRA), and several government laboratories, universities, other government agencies, private companies, and foreign government research entities. The study included: (1) a major program of meteorological measurements for understanding mean and turbulent flow conditions in the urban boundary layer (Brown et al. 2004a; Hanna et al. 2007; Nelson et al. 2007; Ramamurthy et al. 2004); (2) a major program of tracer concentration measurements for tracking the dispersion of a pollutant in this environment (Clawson et al. 2005); (3) an extensive modelling effort designed to improve the ability to predict the movement of toxic plumes in urban environments using the meteorological and tracer concentration databases generated (e.g., Burrows et al. 2007; Chan and Leach 2007; Hendricks et al. 2007); and (4) wind-tunnel experiments (Kastner-Klein et al. 2004). JU03 was conducted from June 28 through July 31, 2003 in Oklahoma City, Oklahoma, situated on the southern U.S. high plains, and was focused in the consolidated core of tall buildings that comprise the downtown Central Business District (CBD). The emphasis was on the effects of the urban canopy and of the thermal regime (night and day) on plume dispersion. Terrain effects were negligible. A complete summary of this study has been provided by Allwine et al. (2004) and Allwine and Flaherty (2006), while the complete JU03 database is available from a website maintained by Dugway Proving Grounds (http://www.ju2003-slc.org).

The large JU03 tracer measurement database is an excellent resource for analyzing plume dispersion in an urban setting. In particular, the fast-response, real-time tracer measurement datasets provide a means of studying plume concentration fluctuations, whose role is a significant factor in evaluating the hazard posed by a plume of toxic material.

Health effects associated with the inhalation of chemical, biological, or other toxic agents are related to the length of exposure, the concentration during the time of exposure, and the specific level of toxicity associated with a given agent. Toxicity assessments are often made in the context of Haber's Law, which relates a specified level of physiological response to a toxin, $k$, to the product of the concentration, $c$, and exposure time, $t$ (i.e., $c t=k$ ) (Witschi 1999). While the use of Haber's Law has been widespread, it is now believed that it is just a special case for relating $c$ and $t$ to $k$ and is not universally applicable (Miller et al. 2000). There is a considerable body of evidence that suggests it underestimates the risk associated with short-term exposures to high concentrations (EPA 1999).

A more accurate and broadly applicable means of assessing the danger posed by exposure is through the concept of toxic load. Toxic load (or dosement) $D$ can be expressed as $c^{n} t$ (Ride 1984; ten Berge et al. 1986; Fairhurst and Turner 1993). The value of the toxicity factor exponent $n$ varies by chemical species with published estimates ranging from $0.8-4.9$ although there is uncertainty about some of these results, especially with respect to the applicability to humans. For varying concentration, dosement can be expressed as $D=$ $\int[c(t)]^{n} d t$; it has also been found that toxicity is related to the intensity of the concentration 

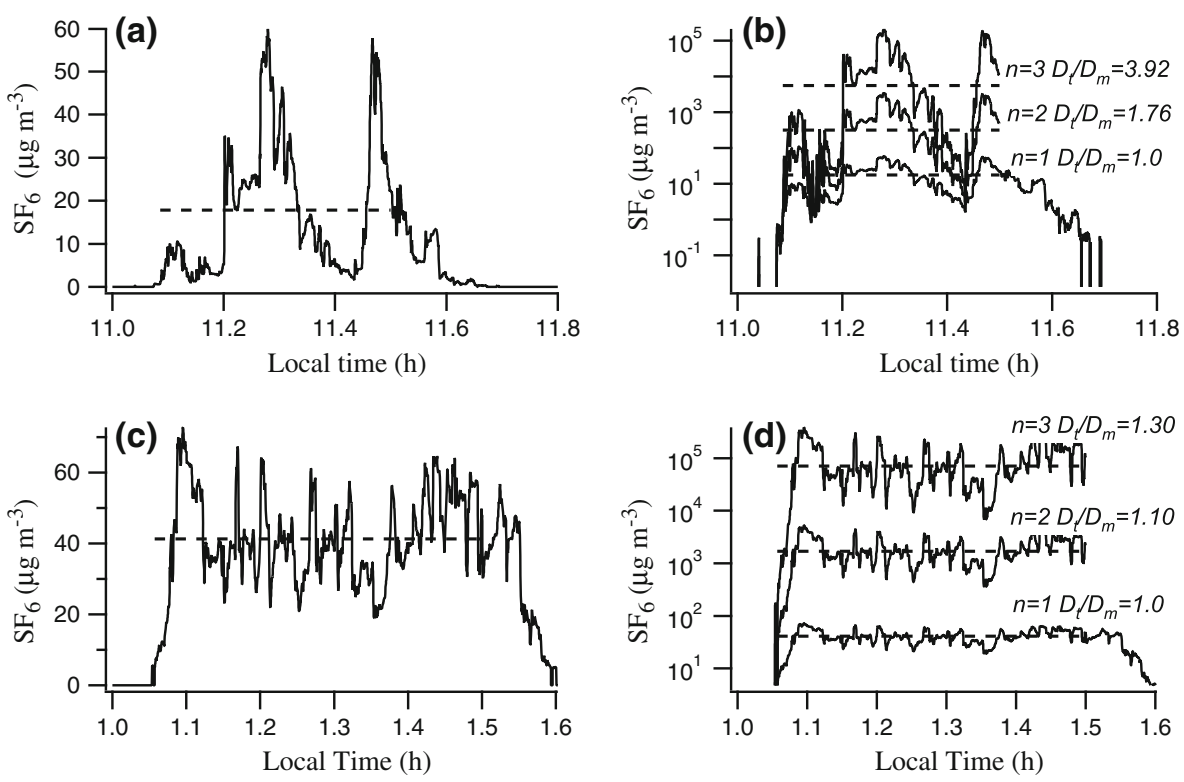

Fig. 1 Example of a tracer concentration time series and the corresponding calculation of dosement for varying $n$ for actual (solid) and mean (dashed) tracer time series: (a) IOP6, release 2, van0 (location on Fig. 2); (c) IOP8, release 2, van1 (location on Fig. 3); (b and d) corresponding calculations of dosement ratios at varying $n$ for actual $\left(D_{t}\right)$ and mean series $\left(D_{m}\right)$ for $(\mathbf{a})$ and $(\mathbf{c})$, respectively

fluctuations. Given the same mean concentration over a specified interval of time, the potential toxic effects associated with a highly fluctuating concentration signal can be greater than for an equivalent uniform signal (Ride 1984). In fact, peak concentrations are considered to be the most important factor in the determination of acute toxic responses in short-term exposures (Kodavanti et al. 1997; EPA 1999; Witschi 1999).

From the expression for $D$ it is clear that dosement is sensitive to $n$ and that a sharply fluctuating concentration time series poses a greater threat than a uniform time series with the same mean value. Examples of this from the JU03 fast-response tracer dataset are shown in Fig. 1, where Fig. 1a is a daytime time series with large concentration fluctuations and Fig. 1b shows the effects of increasing $n$. The ratio of the dosement for the actual concentration time series, $D_{t}$, to the dosement for the mean of the time series, $D_{m}$, increases as $n$ increases. Figure $1 \mathrm{c}$ is a nighttime time series with suppressed concentration fluctuations, and Fig. 1d shows the effect of increasing $n$ in this case.

The need to predict concentration fluctuations was recognized long ago (e.g., Chatwin 1982; Hanna 1984; Mylne and Mason 1991). The experimental verification of urban dispersion models used to guide emergency response has often been limited to comparisons with mean tracer concentrations with averaging times ranging from $5 \mathrm{~min}$ to $1 \mathrm{~h}$ (e.g., Hanna et al. 2003, 2007; Gryning et al. 2005; Venkatram et al. 2005; Flaherty et al. 2007a; Hendricks et al. 2007). Higher frequency concentration fluctuations are not considered. The results shown in Fig. 1 make it clear that the ability to accurately assess the potential hazards associated with a toxic airborne release includes knowledge about the agent toxicity (i.e., $n$ ) and plume concentration fluctuations.

The greater daytime concentration variability relative to the nighttime example seen in Fig. 1a and $\mathrm{c}$ is part of a larger picture of day-night plume dispersion differences observed 
during JU03. These differences were observed in spite of the common finding that the differences in stability regime in an urban atmosphere are minimal between day and night with stability conditions generally in a restricted range of neutral to weakly unstable (e.g., Britter and Hanna 2003). The similarities and differences between overall plume patterns, probability distributions, plume concentration statistics, and vertical concentration profiles for day and night are examined herein using the extensive JU03 tracer database.

Part of the analysis features comparisons of conditionally and unconditionally sampled plume statistics. Unconditional sampling includes all valid data in a time series in the calculations, including zeros, with values defined as zero (below a specified threshold) excluded from the calculation of conditional statistics. Conditional and unconditional sampling highlights some differences between urban and more homogeneous settings.

The analysis of plume concentration fluctuations begins with the calculation of probability distributions and concentration fluctuation intensities as a function of position of the receptor inside the plume and day versus night. Unconditional and conditional plume concentration fluctuation statistics are then calculated. Other evidence including plume contour mapping and vertical concentration profiles is then presented that, together with the previous analyses, identifies important distinctions in plume dispersion regimes between day and night. Finally, the possible roles of wind meander and atmospheric stability in explaining these differences are examined and some comparisons made with results from homogeneous settings.

\section{Experimental Description and Analytical Methods}

JU03 was designed to study plume dispersion in an urban environment based upon the release and downwind measurement of a tracer gas in varying atmospheric conditions. Ten experiments (intensive observational periods-IOPs) were conducted during which the inert tracer gas sulfur hexafluoride $\left(\mathrm{SF}_{6}\right)$ was released from several curbside locations in the CBD at a height of $2 \mathrm{~m}$ and concentrations measured downwind. The tracer releases were executed by the Air Resources Laboratory Field Research Division of NOAA (NOAA ARLFRD). There were six daytime IOPs (1-6) and four nighttime IOPs (7-10), with each IOP consisting of three continuous point-source releases lasting $30 \mathrm{~min}$ each and up to six instantaneous puff releases. Table 1 is a summary of release information for each IOP. Figures 2 and 3 provide an overall picture of the experimental setting and a reference for the description of the tracer measurement arrays that follows.

Two high temporal resolution tracer concentration datasets were collected using two different types of fast-response analysers. The first of these was measured by ARLFRD with an array of nine fixed and one mobile, van-mounted, fast-response $\mathrm{SF}_{6}$ tracer gas analysers (TGA). Sampling was done through an inlet atop each van at about $2 \mathrm{~m}$ above ground level (a.g.1.). The nine fixed TGAs used in the present analysis were deployed downwind of the release site at distances exceeding a city block, mostly ranging from $175-600 \mathrm{~m}$, more in a few instances. The TGA analysers have an approximately $1 \mathrm{~s}$ response time (Benner and Lamb 1985) and data were acquired at a rate of $2 \mathrm{~Hz}$ during measurements. The second array of up to 10 fast-response Miran real-time analysers was deployed at ground level by the Lawrence Livermore National Laboratory in the immediate vicinity of the $\mathrm{SF}_{6}$ release site at distances ranging from $25-150 \mathrm{~m}$, generally within a city block and mostly within line of sight of the release. In rare instances, a Miran analyser was located within about $50 \mathrm{~m}$ of a TGA analyser (e.g., Fig. 2, release 2, Main Street). Data from the Miran analysers were acquired at a rate that varied between instruments and release periods but was commonly about $0.9 \mathrm{~Hz}$. The TGAs use electron capture detection (ECD) and are capable of measuring 
Table 1 Summary of 30-min continuous tracer release periods including start times (Central Daylight Time) and mean wind direction (WD) for each period

\begin{tabular}{|c|c|c|c|c|c|}
\hline IOP & Location & Date & Release & Start (CDT) & $\mathrm{WD}\left({ }^{\circ}\right)$ \\
\hline \multirow[t]{3}{*}{2} & \multirow[t]{3}{*}{ The Westin } & \multirow[t]{3}{*}{ 2-Jul } & 1 & 1130 & 224.2 \\
\hline & & & 2 & 1330 & 204.7 \\
\hline & & & 3 & 1530 & 169.7 \\
\hline \multirow[t]{3}{*}{3} & \multirow[t]{3}{*}{ Botanical Gardens } & \multirow[t]{3}{*}{ 7-Jul } & 1 & 1130 & 185.5 \\
\hline & & & 2 & 1330 & 174.2 \\
\hline & & & 3 & 1530 & 179.5 \\
\hline \multirow[t]{3}{*}{4} & \multirow[t]{3}{*}{ Botanical Gardens } & \multirow[t]{3}{*}{ 9-Jul } & 1 & 1130 & 188.5 \\
\hline & & & 2 & 1330 & 179.7 \\
\hline & & & 3 & 1530 & 183.0 \\
\hline \multirow[t]{3}{*}{5} & \multirow[t]{3}{*}{ Botanical Gardens } & \multirow[t]{3}{*}{ 13-Jul } & 1 & 0930 & 180.7 \\
\hline & & & 2 & 1130 & 213.7 \\
\hline & & & 3 & 1330 & 162.2 \\
\hline \multirow[t]{3}{*}{6} & \multirow[t]{3}{*}{ Botanical Gardens } & \multirow[t]{3}{*}{ 16-Jul } & 1 & 0930 & 189.5 \\
\hline & & & 2 & 1130 & 175.3 \\
\hline & & & 3 & 1330 & 167.8 \\
\hline \multirow[t]{3}{*}{7} & \multirow[t]{3}{*}{ Botanical Gardens } & 18-Jul & 1 & 2330 & 177.5 \\
\hline & & 19-Jul & 2 & 0130 & 193.3 \\
\hline & & 19-Jul & 3 & 0330 & 211.2 \\
\hline \multirow[t]{3}{*}{8} & \multirow[t]{3}{*}{ The Westin } & 24-Jul & 1 & 2330 & 158.0 \\
\hline & & 25-Jul & 2 & 0130 & 158.5 \\
\hline & & 25-Jul & 3 & 0330 & 167.7 \\
\hline \multirow[t]{3}{*}{9} & \multirow[t]{3}{*}{ Park Ave. mid-canyon } & 26-Jul & 1 & 2330 & 169.0 \\
\hline & & 27-Jul & 2 & 0130 & 172.7 \\
\hline & & 27-Jul & 3 & 0330 & 179.3 \\
\hline \multirow[t]{3}{*}{10} & \multirow[t]{3}{*}{ Park Ave. mid-canyon } & 28-Jul & 1 & 2130 & 170.8 \\
\hline & & 28-Jul & 2 & 2330 & 178.8 \\
\hline & & 29-Jul & 3 & 0130 & 195.8 \\
\hline
\end{tabular}

concentration mixing ratios in the low parts per trillion by volume (pptv) range. The Miran analysers use infrared detection and measure concentration mixing ratios in the parts per billion by volume (ppbv) range.

The method limit of detection (MLOD) for the TGA ECD measurements is defined as the lowest possible concentration that can be determined to be statistically different from zero and is calculated as three times the standard deviation of repeated analyses of the lowest possible concentration standard (EPA 2004). This was typically a few tens pptv. The method limit of quantitation (MLOQ) is defined as the lowest concentration that can be determined within $30 \%$ of its actual value and is calculated as 10 times the standard deviation of the same lowest concentration standard. For the TGAs, data values less than the MLOD were set equal to zero and excluded from the calculation of conditionally sampled probability distributions and statistics. Values greater than the MLOD but less than the MLOQ were used without any adjustment. 

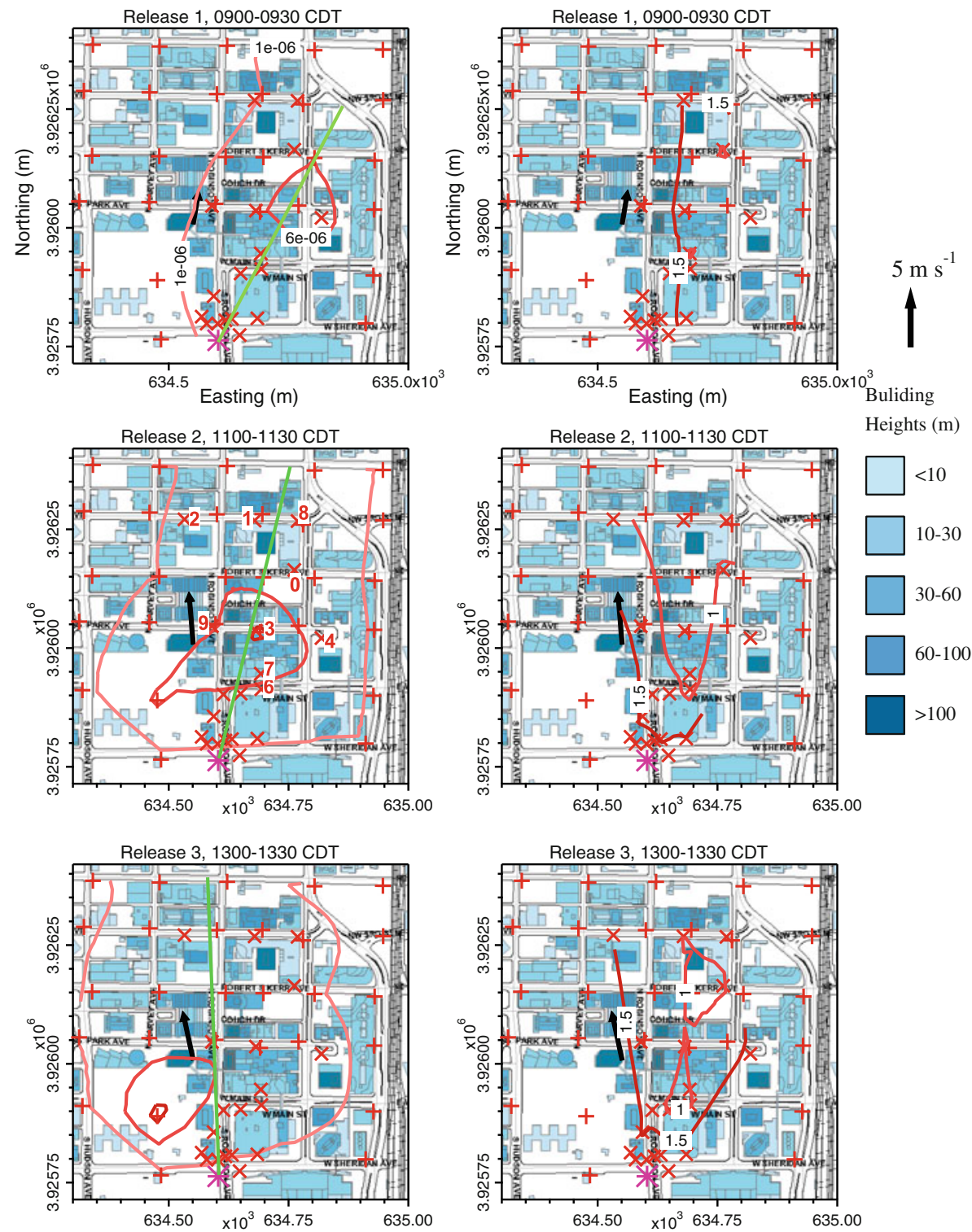

Fig. 2 Normalized mean concentration $\left(\mathrm{s} \mathrm{m}^{-3}\right.$ ) contour maps from street-level PIGS data (left column) and unconditional fluctuation intensity $\left(i_{u}\right)$ contour maps from TGA and Miran data (right column) for the three daytime release periods of IOP6. The ' $*$ ' is the Botanical Gardens tracer release location, ' + ' indicate PIGS sampler locations, ' $X$ ' indicate fast-response analyser locations, green lines are the estimated plume centrelines, and the wind vectors shown are from atop OKT at $127 \mathrm{~m}$ height. Numbers identify TGA van locations for release 2. The cluster of ' $x$ ' near the source are the Miran analysers. For comparison, the mean normalized concentration and intensity contour colours represent the same values in Figs. 2 and 3

At high concentrations the TGAs are susceptible to two sampling artifacts. The first of these is detector saturation, a condition in which the detector becomes saturated and fails to respond, or only responds weakly in a highly non-linear manner, to further increases in 

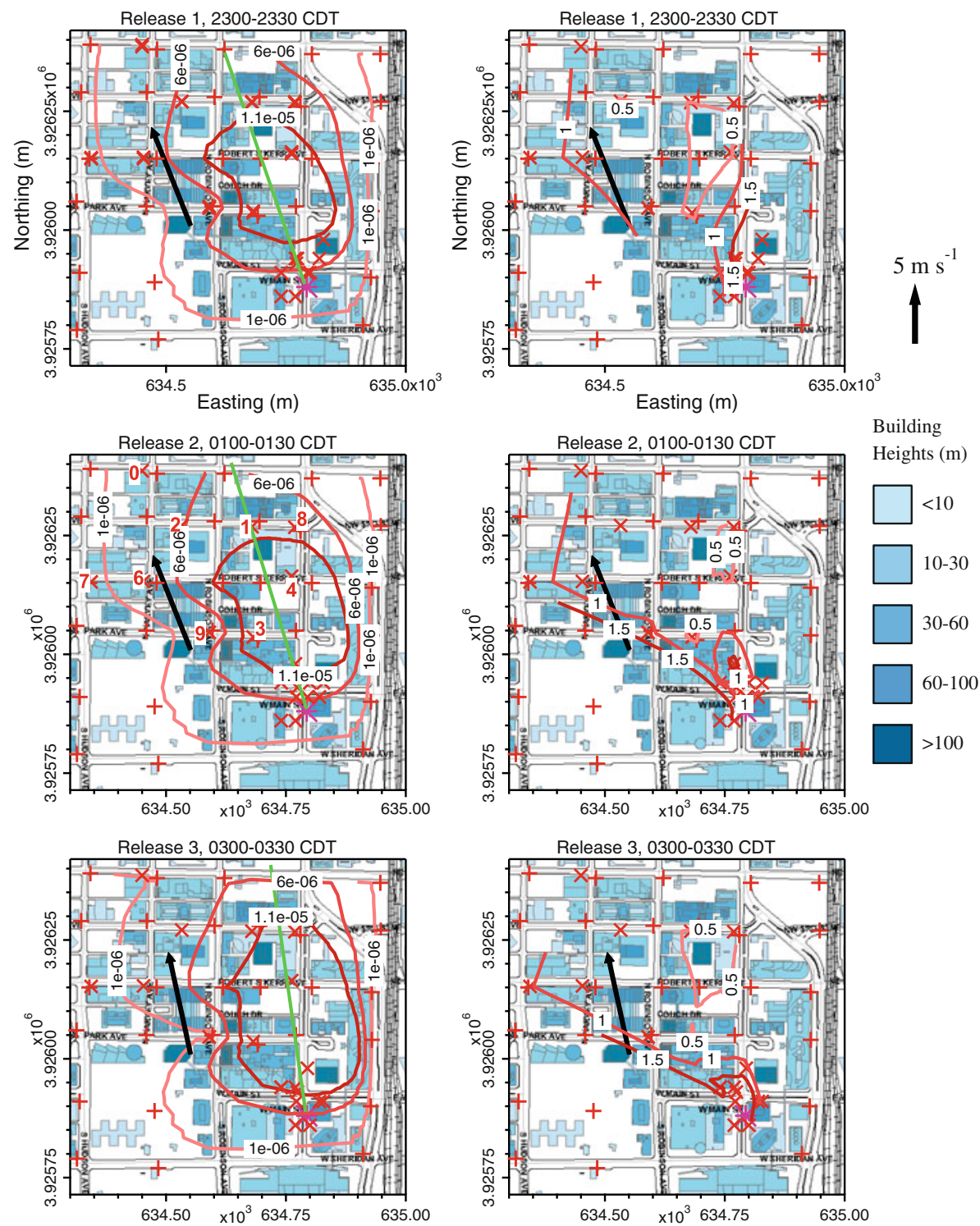

Fig. 3 Same as Fig. 2 except for nighttime IOP8 from the Westin release location

concentration. The second artifact is called "railing" and is the result of the signal exceeding the available voltage range. Either artifact results in concentration peaks that are inaccurately quantified or truncated. The MLOD and effect of these artifacts varied according to IOP and the individual analyser. Peak truncation was more common during daytime IOPs due to higher release rates, $Q$, than during nighttime IOPs. The Miran analysers are not subject to peak truncation. Any 30-min tracer time series exhibiting obvious peak truncation or other signal problems (e.g., gaps in the record due to instrument problems or voltage problems) was not used in the analysis. $\mathrm{SF}_{6}$ mixing ratios were converted to formal concentration units 
$\left(\mu \mathrm{g} \mathrm{m}^{-3}\right)$ and normalized by the release rate $Q\left(\mu \mathrm{g} \mathrm{s}^{-1}\right)$ yielding normalized concentration with units of $\mathrm{s} \mathrm{m}^{-3}$.

Time-averaged tracer concentration measurements, usually integrated over 15 -min periods, were collected by ARLFRD programmable integrating gas samplers (PIGS). These bag samplers were deployed at street and rooftop levels throughout the CBD as well as farther downwind on sampling arcs outside the downtown area. In the CBD, 55 of these samplers were deployed on a high-density, street-level grid on utility poles at $3 \mathrm{~m}$ a.g.1., 10 on rooftops, and four in an underground tunnel system. An additional 65 PIGS were deployed on the downwind sampling arcs at distances of 1,2 , and $4 \mathrm{~km}$ in surrounding residential areas. A detailed summary of the tracer release system and ARLFRD SF 6 tracer gas measurement instrumentation can be found in Clawson et al. (2005). Analysis of the PIGS bag samples was done using ECD-based chromatography and concentration peaks were not subject to truncation.

Plume concentration fluctuation statistics and probability distributions for the normalized TGA concentrations $c$ are calculated for both unconditionally sampled (complete) time series and conditionally sampled (in plume only with zeros removed) time series. Only unconditional statistics and probability distributions are calculated for the Miran analysers due to greater uncertainty in defining zero. Unconditional and conditional are denoted using ' $u$ ' and ' $p$ ' subscripts, respectively. The statistics include the mean concentration $\mu$, standard deviation of concentration $\sigma$, concentration fluctuation intensity $i(=\sigma / \mu)$, skewness $\left(S=\overline{(c-\mu)^{3}} / \sigma^{3}\right)$, and kurtosis $\left(K=\overline{(c-\mu)^{4}} / \sigma^{4}-3\right)$. The mean $\mu$ was calculated for each release period from the first plume arrival time until the end of the 30 - min tracer release period; the plume arrival time was selected when the first distinct sustained signal greater than the MLOQ was detected. Although there was often a significant amount of tracer still present after the release was turned off after $30 \mathrm{~min}$, the records after cessation of the release were not used to eliminate possible ambiguities or inconsistencies. The length of record at each analyser used in the calculations is typically about $20-25 \mathrm{~min}$, and examples of the record lengths used are shown in Fig. 1 by the dashed lines. Probability densities (frequency distributions) for both the TGA and Miran analysers were obtained from histograms of the non-dimensional concentration time series $(c / \mu)$.

Intermittency $(I)$ is commonly defined as the fraction of time when the concentration is non-zero (e.g., Hanna 1984). This definition of intermittency is used here although some have discussed the difficulty in defining intermittency and proposed alternatives (Chatwin and Sullivan 1993; Mole and Jones 1994).

All valid tracer data for IOPs 2-10 are included in the analysis, with IOP1 excluded due to quality problems with much of the tracer concentration data. Table 1 shows that all daytime releases were at the Botanical Gardens with the exception of IOP2; nighttime releases were from the Botanical Gardens, The Westin, and on Park Avenue. It is certain that these differences in release location had effects on downwind tracer measurements. However, the results from IOP7 show more similarity to IOPs $8-10$ than to IOPs 3-6, and IOP2 is more similar to IOPs 3-6 than IOP8 in terms of measures such as $i$ and they are grouped accordingly in the analysis to follow.

The tracer gas measurement part of the experiment was supplemented by an extensive suite of meteorological measurements to provide a detailed characterization of the mean and turbulent atmospheric parameters governing the observed tracer distributions (Brown et al. 2004a; Hanna et al. 2007). Reference is made to extensive turbulence measurement experiments conducted on Park Avenue, though a detailed examination of this dataset is beyond the scope of this paper. The meteorological dataset also includes a set of observations made 
by Pacific Northwest National Laboratory (PNNL) atop the Oklahoma Tower at a height of $124 \mathrm{~m}$ with measurements $3 \mathrm{~m}$ above the building height (OKT, $127 \mathrm{~m}$ a.g.1.). This station is used as a reference for the winds directly over the CBD.

\section{Results}

\subsection{Spatial Reference for the Analysis}

Before proceeding to the main body of analysis, it is first necessary to describe the spatial reference for the analysis and discussion. Conventional plume dispersion theory over homogeneous terrain (Arya 1999) provides a basis for discussion of dispersion in densely built-up urban areas. The theory holds that a plume is moved or laterally shifted by large, low frequency eddies larger than the dimensions of the plume (i.e. meander) while smaller eddies act at lesser scales to alter concentrations by promoting mixing, spreading the plume, and entraining clean air at the margins. The instantaneous concentration observed at a point can be thought of as the combined effects of plume meander and turbulent diffusion about the plume centreline. The concentration time series observed at any given receptor is a function of distance downwind and crosswind position within the plume (Peterson and Lamb 1992, 1995; Yee et al. 1993, 1994) along with other factors including stability, vertical position of the receptor, and surface roughness. With respect to crosswind position, fluctuations in concentration (and intensity $i$ ) are greater near the margins of a plume where the effects of wind meander and the turbulent mixing with clean air are greatest and decrease toward the plume centreline. Intermittency is greatest close to the plume centreline.

With respect to distance, measurement of a plume near the source is dominated by the effects of plume meander and a receptor site is often outside of the plume. Large concentration fluctuations and more numerous occurrences of zero concentration can be expected. Further downwind, as the plume dimensions grow, a given receptor is increasingly likely to be continuously in the plume but a concentration time series still exhibits considerable variability, especially near the margins of the plume. Still further downwind, the plume has grown, internal mixing within the plume begins to smooth out concentration fluctuations, mean concentrations decrease, zero or near-zero concentrations are rare, the importance of plume meander is diminished, and any significant variability is limited to the margins of the plume.

Dispersion in an urban boundary layer can be much more complex than in open homogeneous terrain. An analysis of urban dispersion in the traditional framework of plume centreline, crosswind distance, and downwind distance is more complicated due to the uncertainties that exist as to what the relationship is between the mean wind direction aloft and the actual direction of plume transport at the surface. For example, flow in crosswind-oriented street canyons was commonly channelled in the along-canyon direction with the direction keenly sensitive to small changes in wind direction during JU03 (Klein and Clark 2007; Nelson et al. 2007). This had the effect of shifting the plume laterally in a direction offset from the centreline suggested by the wind direction as it passed through the CBD (Flaherty et al. 2007a). This could amount to several tens of degrees. Belcher (2005) also found enhanced lateral dispersion effects due to wind direction changes within an urban canopy, and noted the importance of "topological dispersion" within about $1 \mathrm{~km}$ from the source in which the plume is split and re-split when dividing streamlines impinge upon buildings with significant effects on lateral dispersion. The limited number of TGA analysers (nine maximum) 
and their irregular spatial distribution also added to the difficulty of interpreting the JU03 concentration fluctuation fields within the traditional crosswind and downwind framework.

For these reasons, our analysis does not use the traditional framework with wind as a reference but instead uses down-plume and cross-plume distances. These were determined by reference to the estimated plume centrelines that, in turn, were determined by the timeintegrated, normalized mean concentration measurements made by the PIGS sampling array. Examples of centrelines with normalized mean PIGS concentration contours and the location of the PIGS samplers used for contouring are shown in Figs. 2 and 3. All TGAs with valid records in IOPs 2 through 10 were fixed in this frame of reference of down-plume $(x)$ and cross-plume (y) positions and used in the analysis. All Miran analysers were segregated into their own group for analysis due to their close proximity to the source, their use of a different tracer measurement method, and locations mostly in line-of-sight to the release (versus direct flow interference by multiple buildings for the TGA measurements). The closure of lower concentration contours close to the source is an artifact of the fact that there were no PIGS in the immediate vicinity of the release.

Additionally, probability densities are classified using concentration fluctuation intensity $i$, and $i$ will be a proxy spatial reference. Lewellen and Sykes (1986) previously used $i$ to classify probability densities. As described above, larger $i$ tend to be associated with receptors that are located nearer the margins of the overall plume (i.e., greater crosswind/cross-plume distances from the "centreline") and close to the source. Smaller $i$ tend to be associated with receptors that are located closer to the nominal plume centreline and further downwind after greater mixing has taken place.

\subsection{Observed Exceedance Probabilities}

The exceedance probability distributions $\operatorname{Pr}$ for $c>c / \mu$ for the TGA and Miran measurements are shown in Figs. 4 and 5, respectively. These are the complement of the cumulative distribution function with zeros included for the unconditional cases. They show that the observed probability distributions are clearly related to the intensity $i$ with the probability of measuring concentrations at ever higher multiples of the mean increasing as $i$ increases. They also show that there are only minor differences between the unconditional and conditional probability densities for the same $i$. As expected, many more of the observed probability densities for the Miran measurements fall within higher $i$ classifications due to their proximity to the tracer source.

Representative model curves for each $i$ classification for the Gaussian (clipped-normal), log-normal, and exponential probability density functions are also shown in Fig. 4. The forms of the probability density function $P(c)$ for the clipped-normal

$$
P(c)=\frac{1}{\sqrt{2 \pi} \sigma_{u}} \exp \left(-\frac{\left(c-\mu_{u}\right)^{2}}{2 \sigma_{u}^{2}}\right)+(1-I) \delta(c)
$$

and exponential

$$
P(c)=\left(I^{2} / \mu\right) \exp (-I c / \mu)+(1-I) \delta(c)
$$

distributions are taken from Mylne and Mason (1991), where $\delta$ is the Dirac delta function. The intermittency $I$ was determined by subtracting 1.0 minus the probability, $A$, of $c=0$ given by the relationship

$$
A=\frac{1}{2}\left[1-\operatorname{erf}\left(\mu_{u} / \sigma_{u} \sqrt{2}\right)\right]
$$



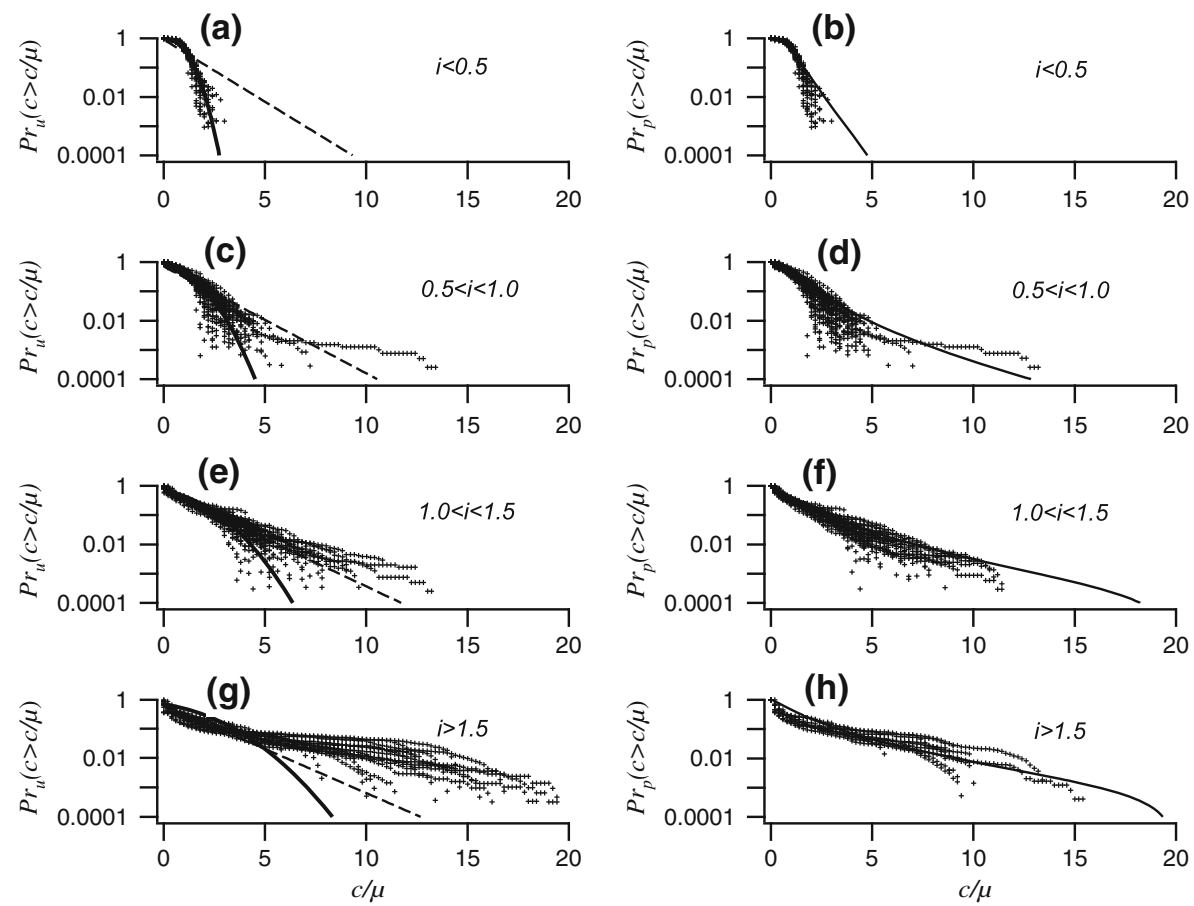

Fig. 4 Unconditional $\left(P r_{u}\right)$ and conditional $\left(P r_{p}\right)$ exceedance probability distributions for TGA measurements classified by intensity $i$ : $(\mathbf{a}, \mathbf{b}) i<0.5$; $(\mathbf{c}, \mathbf{d}) 0.5<i<1.0$; (e, f) $1.0<i<1.5$; (g, h) $i>1.5$. The model Gaussian (bold solid), log-normal (solid), and exponential (dashed) distributions are shown for value of $i$ at the top of the corresponding range (for $i>1.5$ model $i=2.0$ )

as described in Lewellen and Sykes (1986) for the clipped-normal distribution. The log-normal distribution (Csanady 1973) is given by

$$
P(c)=\frac{1}{c \sigma_{l} \sqrt{2 \pi}} \exp \left(-\frac{\left(\ln c-\mu_{l}\right)^{2}}{2 \sigma_{l}^{2}}\right)
$$

where $\mu_{l}$ and $\sigma_{l}$ are the mean and standard deviation of the natural logarithm of $c$, respectively.

For $i<1$, the clipped-normal distribution provides a good approximation for the data while the log-normal and exponential distributions exaggerate the probability of higher concentrations. However, for $i>1$, the clipped-normal distribution under-predicts the occurrence of higher concentrations, the exponential distribution offers a better representation of the data, and the log-normal distribution provides good fits to the data. The slight convex curvature of the log-normal model curve at large $i$ and $c / \mu$ (Fig. 4h) is due to cutting off the calculation for $c / \mu>20$.

The presence of concavity in the data distributions at lower $c / \mu$ as $i$ increases is due to the fact that increasing fractions of the data are zeros or near zeros. The concavity at lower $c / \mu$ is not present at lower $i$. The log-normal model does not accommodate zeros, therefore this low $c / \mu$ flexure is not picked up. The clipped-normal model accounts for the zeros resulting in shifting the start point of the clipped-normal model curve downward. Outlier distributions (e.g., Figs. 4c-d) and other data scatter should be regarded as reflecting a limited sample size and the stochastic nature of the underlying process. 
Fig. 5 Unconditional $\left(\mathrm{Pr}_{u}\right)$ exceedance probability distributions for Miran measurements classified by intensity $i$ : (a) $0.5<i<1.0$; (b) $1.0<i<1.5$; (c) $1.5<i<2.0$; (d) $i>2.0$. The model log-normal (solid line) distribution is shown for a value of $i$ at the top of the corresponding range
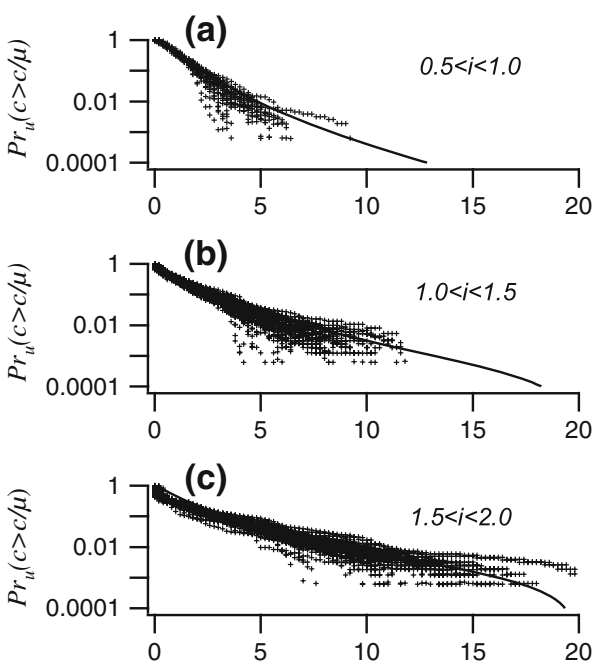

(d)

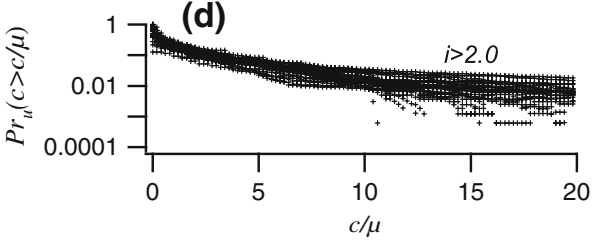

These results are compared with previous studies in more homogeneous terrain that examined which probability distributions provided the best fit to their data. Lewellen and Sykes (1986) found the clipped-normal distribution worked well for their data at distances exceeding $1 \mathrm{~km}$. Mylne and Mason (1991) also found the clipped-normal distribution probability density function worked well for their data at distances from 50-1000 m although the exponential function was better close to the source where the clipped-normal tended to underestimate high concentrations. At distances of 25 and $100 \mathrm{~m}$, Sawford (1987) also reported favourable results for the clipped-normal distribution but problems with the log-normal distribution. However, it was noted that the clipped-normal did not account for conditional $i_{p}>1$. Yee and Chan (1997) found a clipped-gamma model was superior to the clipped-normal. Yee et al. (1993) found log-normal and gamma distributions provided better estimates of probabilities in quantile-quantile plots for non-zero concentrations in near-neutral conditions at $x$ of 50 and $100 \mathrm{~m}$ than did the exponential or clipped-normal distributions. For more stable conditions, the gamma distribution was superior. The same study also found, however, that the log-normal distribution did not work well in comparisons of conditional concentration statistics for $i, S$, and $K$.

There appears to be some correspondence between the quality of fit for a particular distribution, distance from the source, and fluctuation intensity in these earlier studies. In general, the exponential and log-normal distributions seem to work better at lesser downwind distances with larger fluctuation intensities, and the clipped-normal distribution appears to work better at larger downwind distances where intensities have decreased. This is consistent with the results reported here. 


\subsection{Concentration Statistics}

Figure 6 shows how the intensity $i_{u}$ varies with distance and the approximate absolute value of the crosswise position within the plume for the TGA measurements. It also compares day and night results. The Miran data are not used in Fig. 6 due to the very large uncertainty as to how to define the plume centreline in very close proximity to the source in the highly heterogeneous urban environment.

As expected, $i_{u}$ increases as downwind distance decreases, and also tends to increase as the distance from the plume centreline increases. Second, $i_{u}$ is usually less for the nighttime results than the daytime results except close to the source, where distinctions between day and night for $i_{u}$ are less clear.

Outlier data seen in Fig. 6 are probably attributable, at least in part, to the uncertainty involved with fixing the plume centreline and relative location of the receptor within the plume. However, it can also be seen that outlier data are mostly closer to the source where greater variability is expected. The occurrence of outliers tends to diminish further downwind. A final consideration regarding the outliers is that some of the most prominent are from daytime cases near the source (e.g., Fig. $6 \mathrm{~b}$ at about $170 \mathrm{~m}$ cross-plume distance). This might be related to a pattern of day-night differences, a topic that will be more fully developed later.

Combining the results of Figs. 4, 5, and 6 it can be inferred that there was little probability of observing concentrations greater than five times the mean close to the plume centreline, especially at night. Higher multiples of the mean concentration are more likely to be observed as cross-plume distance from the centreline increases or downwind distance decreases.

Figure 7 compares unconditional and conditional sampling statistics for $i, S$, and $K$ in the TGA measurements as functions of actual measured intermittency $\left(I_{m}\right)$. There is little difference between the unconditional and conditional results for higher values of $I_{m}$. Note that most of the $I_{m}$ values for the TGAs are high, in fact, about 1.0 or so. Larger differences are observed for lower values of $I_{m}$. A direct comparison between the unconditional and conditional values for $i, S$, and $K$ makes this even clearer (Fig. 8). Except for some modest outliers, there is an approximate one-to-one correspondence, especially at lower values of $i$, $S$, and $K$. The similarity between conditional and unconditional statistics is consistent with the similarity between probability distributions in Fig. 4. The possible significance of these observations with respect to contrasts between urban and homogeneous plume dispersion will be discussed later.

The mean and standard deviations for unconditional $i, S$, and $K$ for the daytime Miran measurements are $1.74 \pm 0.72,2.92 \pm 1.59$, and $13.26 \pm 17.23$, respectively, while the mean and standard deviations for $i, S$, and $K$ for the nighttime measurements are $1.73 \pm$ $1.01,3.27 \pm 2.01$, and 17.21 \pm 21.56 , respectively. These values of $i, S$, and $K$ for the Miran measurements are larger in value than the TGA measurements due to their close proximity to the source (compare in Figs. 2 and 3). The Miran $i, S$, and $K$ indicate little difference between day and night. Hypothesis testing using the null hypotheses that the Miran daytime and nighttime populations of $i, S$, and $K$ are the same are all accepted at $\alpha=0.05$.

The skewness and kurtosis values for both the TGA and Miran measurements are clearly much different than those for a Gaussian distribution $(S=0, K=3)$ and indicate that most of the measured distributions in JU03 are positively skewed and non-Gaussian with long tails. This observation has a bearing on the day-night differences discussion to come.

Other studies from more homogeneous settings have also reported similar values for $i, S$, and $K$, with a decrease as downwind distance increases. For distances ranging from $50-1000 \mathrm{~m}$ in near-neutral conditions, Mylne and Mason (1991) found that $i$ was a function of travel time. They reported $i_{u}$ ranging from about $3-6$ for $x=63 \mathrm{~m}$ and about $1-5$ for 
Fig. 6 TGA unconditional intensities $i_{u}$ for day (filled circle) and night (open circle) as a function of the absolute value of distance from the plume centreline and downplume distance: (a) $<200 \mathrm{~m}$;

(b) 200-300 m; (c) 300-400 m; (d) 400-500 m; (e) $>500 \mathrm{~m}$; (f) as a function of distance along the plume centreline for cross-plume distances less than $100 \mathrm{~m}$
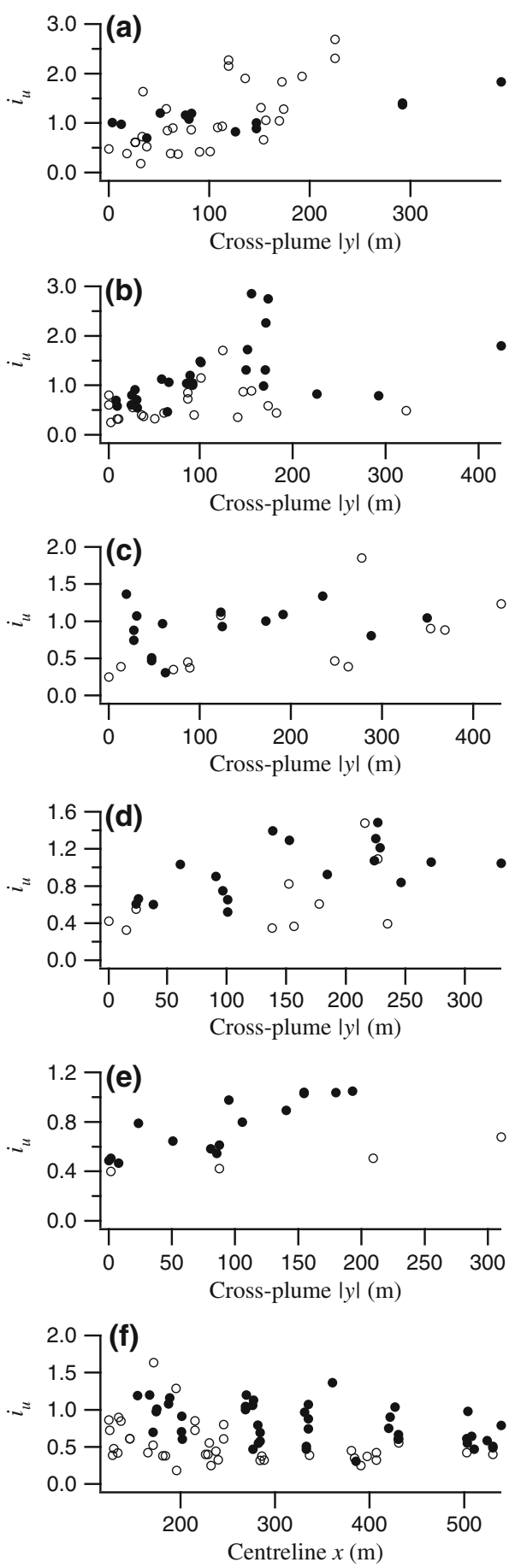

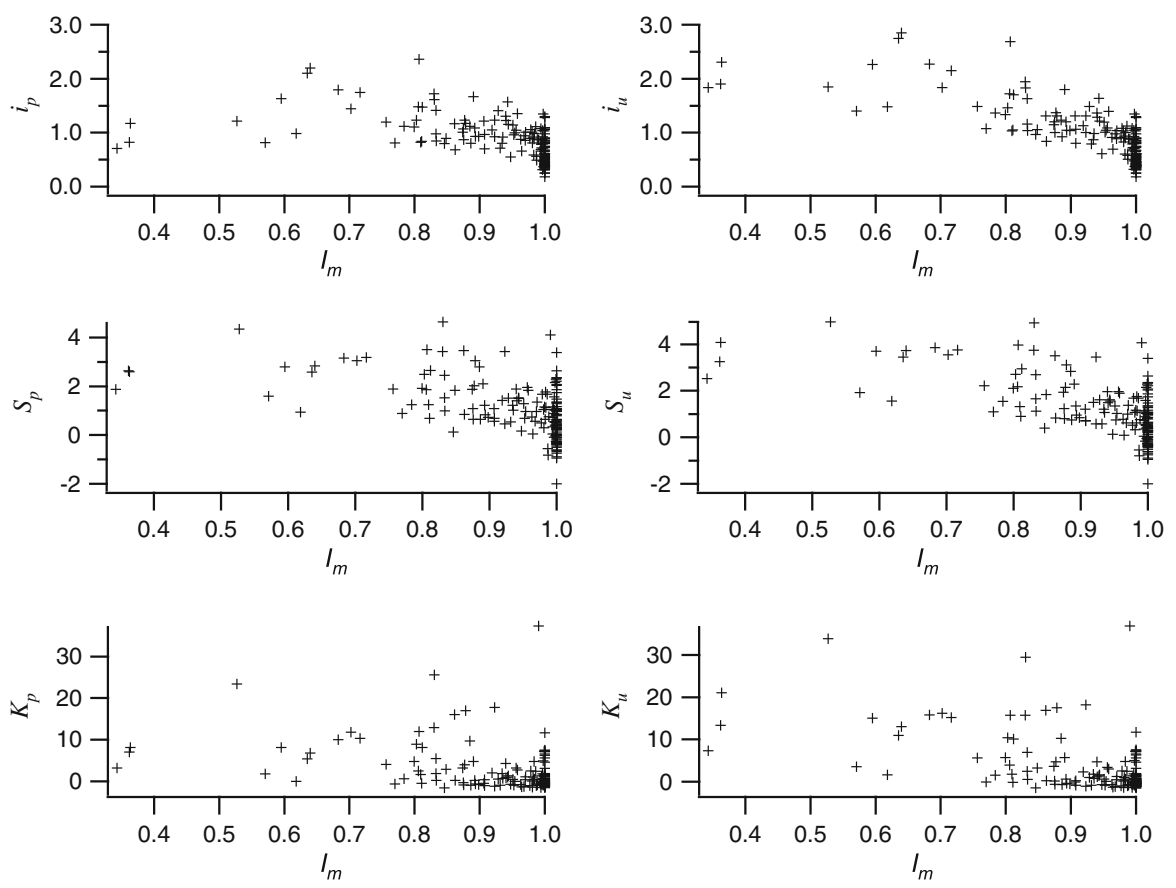

Fig. 7 Conditional $(p)$ and unconditional $(u)$ intensity, skewness, and kurtosis as a function of the measured intermittency $I_{m}$

$x=740 \mathrm{~m}$, depending on cross-plume distance. Conditional $i_{p}$ values were distinctly smaller and less variable. At distances ranging from $25-100 \mathrm{~m}$ for a range of stability conditions, Yee et al. (1993) found $i_{u}$ mostly $1-10, S_{p}$ mostly $1.5-4$, and $K_{p}$ mostly 5-20. Conditional $i_{p}$ were much less. Sykes and Henn (1992) reported $i$ from about 1.3 to 2.0, peaking at a distance of $x / H_{b}=2$, where $H_{b}$ is the boundary-layer depth, and decreasing beyond that. Lewellen and Sykes (1986) found $i$ mostly in the range of $0.4-1.5$ at distances from $1-3 \mathrm{~km}$ with sometimes larger values at greater distances. At distances of 5-15 m, Mole and Jones (1994) reported $i$ from 3.1-5.7, $S$ from 4.3-9.3, and $K$ from 23-168 in unstable conditions. The values were all much lower in stable conditions.

\subsection{Differences Between Daytime and Nighttime}

As already seen, there were some differences in plume dispersion between day and night during JU03. Figure 1 shows example daytime and nighttime time series that are very different in character but at similar downwind and cross-plume distances. The daytime time series shows large magnitude concentration fluctuations and a sort of periodicity, whereas the nighttime time series shows much less variability. Additional evidence of these day-night differences will be listed here. Possible explanations for these day-night differences will be examined in Sect. 4.

Other aspects of this day-night difference can be seen by comparing Figs. 2 and 3. Given that the contour interval scheme for the normalized mean concentrations is common to Figs. 2 and $3\left(1 \times 10^{-6}\right.$ (light red) to $1 \times 10^{-5}$ (dark red) at $5 \times 10^{-6}$ increments), it can be seen that there are clear differences between the daytime (Fig. 2) and nighttime (Fig. 3) 
Fig. 8 Comparison between unconditional $(u)$ and conditional (p) intensity, skewness, and kurtosis. The lines are 1:1 references
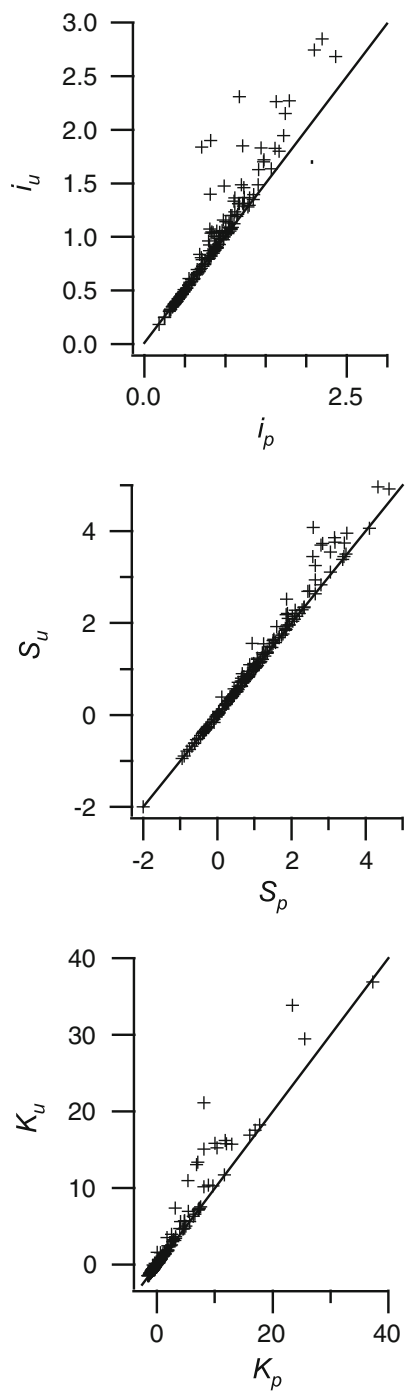

normalized concentration footprints. The normalized mean concentration footprints in Fig. 3 have significant areas with concentrations above the maximum contour value whereas concentrations exceeding the upper contour in Fig. 2 are very sparse. Even the area covered by the intermediate value contour in Fig. 2 is much smaller than the corresponding contour in Fig. 3. This pattern of smaller normalized concentrations in the daytime IOP6 relative to the nighttime IOP8 is also observed in the other daytime and nighttime IOPs of JU03. Similarly, some parts of the CBD have fluctuation intensity values less than 0.5 during IOP8 whereas such areas are absent from IOP6. Again, this day-night contrast in $i$ during IOPs 6 and 8 is consistent with the other day and night IOPs. Note this is consistent with the observations of Fig. 1. Figure 6 also illustrates this pattern of higher daytime $i$, except perhaps near the source where the picture is more ambiguous.

The higher nighttime, normalized, street-level, PIGS concentrations implies that a larger fraction of the tracer vented upwards during the daytime compared to nighttime. 

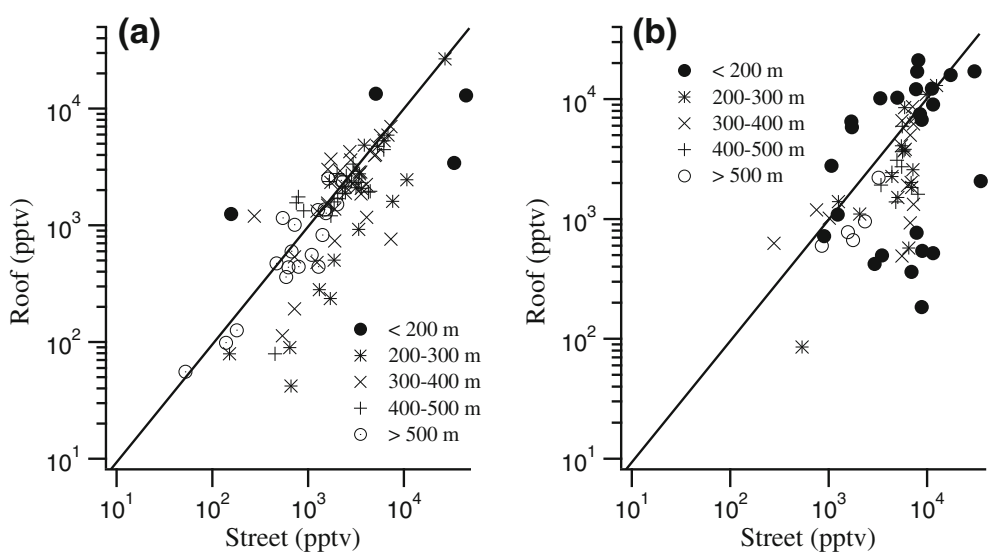

Fig. 9 Comparison of vertically collocated (a) daytime and (b) nighttime PIGS tracer concentrations at street and rooftop levels as a function of distance from the release. The lines are 1:1 references

Flaherty et al. (2007a) also found that vertical concentration profiles $1 \mathrm{~km}$ downwind of the release indicated lower normalized concentrations, more uniform vertical distributions, and enhanced dispersion during the day compared to night.

Figure 9 compares the results for 10 pairs of vertically collocated street-level and rooftop level PIGS bag sampler results. With few exceptions, pairs were located within $20 \mathrm{~m}$ horizontally. For distances less than $200 \mathrm{~m}$ from the release site, both day and night exhibit poor agreement between street and rooftop levels. Beyond $200 \mathrm{~m}$, however, while there is still considerable scatter, the street and rooftop level concentrations during the daytime tend to exhibit an approximate 1:1 correspondence. In contrast, the street and rooftop level concentrations for the nighttime IOPs are more poorly correlated with a distinct bias in favour of higher street-level concentrations. Beyond $200 \mathrm{~m}$ the combined daytime IOPs have linear regression slope, intercept, and $r^{2}$ values of $0.83,-79$, and 0.79 with normalized mean square error and fractional bias values of 0.42 and 0.22 , respectively. The corresponding nighttime values are $0.76,-665,0.47,0.55$, and 0.46 , respectively. These results suggest that vertical mixing during the daytime IOPs was largely complete and effective beyond about $200 \mathrm{~m}$ whereas vertical mixing was relatively suppressed at night. The widely diverging results shown for nighttime at less than $200 \mathrm{~m}$ represent measurements where building-driven circulations, particularly in the Park Avenue canyon, likely played a key role by producing much higher concentrations at rooftop levels in some cases. Recall that releases for IOPs 9 and 10 were in the Park Avenue canyon (Table 1; Park Avenue is indicated on Figs. 2 and 3). Eighteen out of the 24 nighttime points less than $200 \mathrm{~m}$ were measured during Park Avenue releases.

These results should be examined with respect to the location of the collocated PIGS samplers. Three of the 10 pairs were located along Park Avenue with rooftop heights of 117, 16, and $47 \mathrm{~m}$ a.g.l., and were about $300 \mathrm{~m}$ from the Botanical Gardens release site. Four pairs were located between Kerr and McGee (next avenue north of Kerr) avenues with rooftop heights of 29, 78, 115, and $26 \mathrm{~m}$ a.g.l., and were about 400-450 $\mathrm{m}$ from the Botanical Gardens site. The remaining pairs were located just north of McGee Avenue with rooftop heights of 26, 20, 37, and $72 \mathrm{~m}$ a.g.1., and were about $550 \mathrm{~m}$ from the Botanical Gardens site. The Westin release site was closer to these vertically paired PIGS than the Botanical Gardens release site by about $100 \mathrm{~m}$. The Park Avenue release site was still closer with maximum distances 
of about $300 \mathrm{~m}$ from the McGee Avenue samplers. Since most daytime releases were made from the Botanical Gardens site and three of four of the nighttime releases were made from the Westin or Park Avenue sites, the results shown in Fig. 9 are not directly comparable due to the differences in building heights. However, if the two heights in excess of $100 \mathrm{~m}$ are excluded, the mean heights for each of the 3 sets listed above are roughly comparable at 31.5 , 44.3 , and $38.8 \mathrm{~m}$, respectively. The consistency of the bias, especially as distance increases, suggests that the enhancement of vertical mixing during daytime was real.

The observation was made in Fig. 4 that the clipped-normal distribution provided a better fit to the data for $i<1$ and that the other distributions, especially log-normal, provided much better fits to the data for $i>1$. When the individual time series frequency distributions are composited by estimated downwind and cross-plume distances, it is found that the form of the composite distributions is best approximated by either Gaussian or log-normal or multiple, mixed modes depending upon relative plume position and considerations of day-night. The Gaussian frequency distribution is non-skewed $(S=0)$ and features a dominant mode near $c / \mu=1$ with short tails on the distribution. In contrast, the log-normal or exponential frequency distributions are positively skewed $(S>0)$ with a dominant mode closer to zero and long tails on the distribution. Mixed modes in JU03 were sometimes dominated by two frequency modes (bimodal), one near zero and one near 1.0, but multiple prominent modes were also common. Excluding relative plume location, the differences observed in the composited frequency distributions are attributable to day-night differences.

Figure 10 provides a snapshot of the compositing analysis using all of the TGA results for release period 2 of IOPs 6 and 8. To gain a sense of the spatial relationships between the frequency distributions, the locations of the TGA vans in Fig. 10 are indicated in Figs. 2 and 3. Figure 10a (daytime) shows multiple modes but with none clearly dominant. However, there is a strong tendency for the maximum peaks in the frequency distributions to lie between zero and 0.5 and are best approximated by the log-normal. Vans 6 and 7 show evidence of the "railing" described earlier due to the termination of the frequency distributions with a sharp increase in frequency. In the absence of railing, these values would be distributed into longer tails at higher values of $c / \mu$. In general, TGAs located closer to the release or edges of the plume are more likely to have purely log-normal-like frequency distributions with a dominant mode approaching zero (e.g., vans 4 and 9) whereas TGAs located closer to the plume centreline or further downwind are more likely to exhibit multiple modes (e.g., vans $1,3,8)$.

Figure 10b (night) provides a different picture. While other modes are present, and there is even a log-normal frequency distribution included (van 9), the clearly dominant mode in a composite sense is around $c / \mu=1$ and the overall appearance of the composited frequency distributions approaches that of a Gaussian.

The Gaussian form in Fig. 10b with a prominent composited mode near the mean (i.e., $c / \mu=1$ ), low probabilities of low concentrations, and abbreviated tails for high concentrations, is typical for JU03 nighttime results near the plume centreline at distances exceeding $200 \mathrm{~m}$. In contrast, multiple modes are commonly present in the daytime data near the plume centreline within the range of distances encompassed by the experiments. Multiple modes are also observed in the nighttime data but are much less prevalent than during the day. Yee et al. (1994) also noted multiple modes in near-neutral stability conditions in a homogeneous flow setting. The individual log-normal-like frequency distributions included in Fig. 10, with a prominent mode near $c / \mu=0$ and long tails, are typical for the daytime and nighttime results near the margins of the plume or at downwind distances of less than $200 \mathrm{~m}$.

While there is considerable variation within daytime and nighttime results, the examples shown in Figs. 1 and 10 are representative of a relatively consistent pattern of differences 
Fig. 10 Relative frequency distributions for all TGA time series for release period 2 for (a) IOP6 and (b) IOP8. Locations of the TGA analysers are indicated on Figs. 2 and 3 for IOPs 6 and 8, respectively
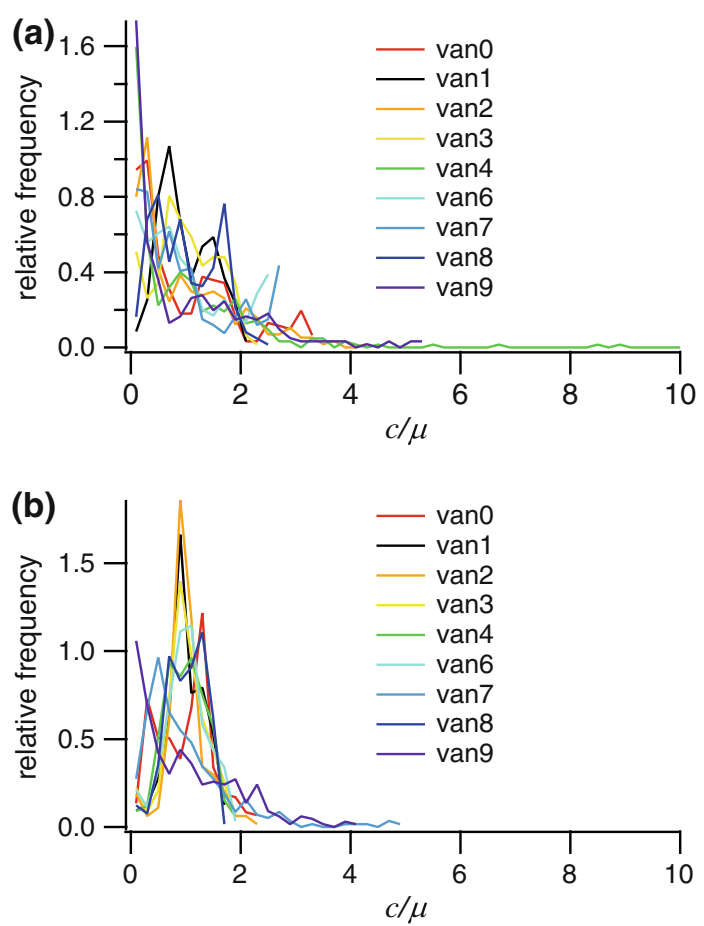

between daytime and nighttime series. Given a plume position with $x>200 \mathrm{~m}$ and away from the margins of the plume, daytime time series are much more likely to exhibit large tracer concentration fluctuations with frequent low values and numerous peak values well above the overall mean. In contrast, nighttime time series are much more likely to exhibit relatively suppressed concentration fluctuations except near the margins of the plume or close to the source. The evidence indicates that at night the tracer typically arrived in a major pulse, lingered with less concentration fluctuation, and then gradually dissipated after the release had ended. Both the day and night results exhibit large concentration variability at the margins of the plume. However, only the daytime results consistently exhibit large concentration variability closer to the centre of the plume. This daytime variability within the heart of the plume was present both near the release as well as further downwind. Flaherty et al. (2007a) also found that there was greater variability in the tracer signal during the daytime (IOPs 5 and 6) than at nighttime (IOPs 8 and 9) at a site $1 \mathrm{~km}$ downwind of the release. Yee et al. (1993) and Mylne and Mason (1991) also found in-plume fluctuation intensity, skewness, and kurtosis decreased as atmospheric stability increased in experiments conducted in more homogeneous settings.

In spite of the observed differences between daytime and nighttime, there are only minor differences when the exceedance probability distributions are grouped by day and night and classified by $i$ (Fig. 11). This suggests that while the mechanisms driving dispersion in JU03 varied between day and night, the end results appear to be a function of $i$. The most notable difference is that some nighttime plots have a larger population of longer-tailed probability densities than the corresponding daytime plots for the same $i$ (e.g., compare $\mathrm{k}$ and $\mathrm{l}$ ). Figure $11 \mathrm{f}$ and $\mathrm{h}$ also show a few outlier distributions relative to $11 \mathrm{e}$ and $11 \mathrm{~g}$, respectively. These differences are largely attributable to the railing artifact that results in the exclusion of 

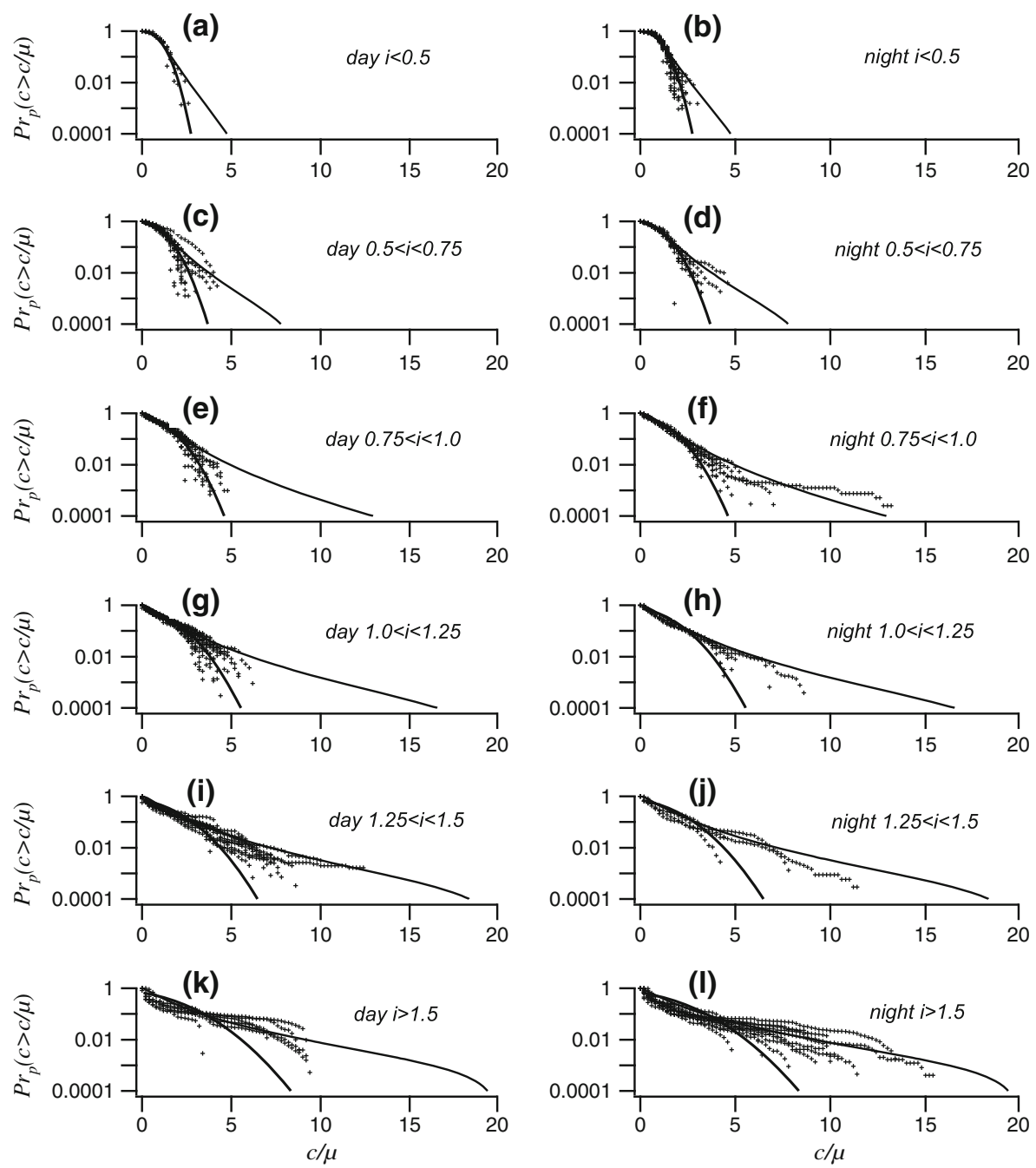

Fig. 11 Conditional $\left(P r_{p}\right)$ exceedance probability distributions for TGA measurements classified by day (left) and night (right) and by intensity $i$ : $(\mathbf{a}, \mathbf{b}) i<0.5$; (c, d) $0.5<i<0.75 ;$ (e, f) $0.75<i<1.0 ;(\mathbf{g}, \mathbf{h})$ $1.0<i<1.25 ;(\mathbf{i}, \mathbf{j}) 1.25<i<1.5 ;(\mathbf{k}, \mathbf{l}) i>1.5$. The model Gaussian (bold solid) and lognormal (solid) distributions are shown for a value of $i$ at the top of the corresponding range

many daytime time series that have large concentration fluctuations. In particular, note the smaller population of distributions and their truncation in Fig. 11k relative to Fig. 111. This is due in significant part to the many more daytime cases with large concentration fluctuations that were omitted from this analysis due to TGA analyser railing. Also note the larger population of nighttime samples close to the source where larger concentration fluctuations are prevalent (Fig. 6). The differences in longer-tailed densities would have likely been eliminated if the daytime data were fully represented. From the presence of the outliers in Fig. $11 \mathrm{f}$ and $\mathrm{h}$ it might also be suggested that the transition from Gaussian to log-normal begins to occur at somewhat lower values of $i$ in the nighttime data. 


\section{Discussion}

A discussion regarding the origin of the differences in concentration variability between day and night is in order. We believe the differences are attributable to a combination of wind direction and meander, release location, stability conditions in the approach flow, and convective mixing. Obviously, every combination of release location within a particular urban canopy, wind speed and direction, stability, and turbulence conditions represents a unique dispersion scenario. Even relatively small changes in any of these parameters might have had significant effects at a particular receptor. In the present analysis, most of the daytime data included in the analysis are from the same release site with proximately south to southwesterly winds (Table 1). In contrast, the nighttime IOPs represent three different release sites and include cases with wind directions from the south-south-west, proximately south, and south-south-east. Computational fluid dynamic (CFD) modelling simulations found that the JU03 concentration field was keenly sensitive to small changes in wind direction and source location (Flaherty et al. 2007b). Wind-tunnel experiments identified differences in dispersion regimes between source locations near the Botanical Gardens site and a source location deeper within the CBD (Kastner-Klein et al. 2004).

During the daytime in JU03, receptors near the plume centreline were very susceptible to large, abrupt incursions of clean air interacting with the plume and affecting concentrations. In this situation, a few pulses of tracer often constituted most of the tracer measured over a 30 min period so that the peak values were considerably greater than the mean. In contrast, this was much less common at nighttime. Nighttime time series are associated with a diminished frequency of zero and near-zero concentrations at sampling locations similarly located near the plume centreline. Concentration fluctuations tended to occur about the mean rather than being dominated by non-equilibrium processes that introduced abrupt changes and large variability (e.g., shifts in wind direction). Receptors at greater distances from the plume centreline were affected by both wind meander and being positioned near the margins of the plume and were subject to large concentration variability during the day and night. Finally, many of the daytime and a few nighttime composite frequency distributions feature multiple modes. We believe this is due to the strong influence of both in-plume fluctuations about the mean and non-equilibrium factors.

Any explanation for these observations requires consideration of, (1) wind direction and meander, and (2) stability effects on turbulence and the flow field. A case can be made that wind meander contributed to the observations. In this context, Table 2 shows that the standard deviation in wind direction, $\sigma_{\theta}$, was larger during the day than night. Concentrations would have abruptly increased/decreased as lateral meander swept contaminated/clean air across an analyser with corresponding changes in variability and mean concentration. Klein and Clark (2007) and Nelson et al. (2007) documented how flow in crosswind-oriented street canyons was commonly channelled in the along-canyon direction with the direction keenly sensitive to small changes in wind direction during JU03. Flaherty et al. (2007a) also found greater variability in wind direction during the day and linked it to the variations observed in

Table 2 Standard deviation in wind direction $\left(\sigma_{\theta},{ }^{\circ}\right)$ during the IOP release periods at the Oklahoma tower (OKT)

\begin{tabular}{|c|c|c|c|c|c|c|c|c|c|}
\hline \multirow[b]{2}{*}{ IOP } & \multicolumn{5}{|l|}{ Day } & \multicolumn{4}{|c|}{ Night } \\
\hline & 2 & 3 & 4 & 5 & 6 & 7 & 8 & 9 & 10 \\
\hline$\sigma_{\theta}$ & 32.9 & 29.1 & 32.6 & 19.1 & 26.8 & 12.1 & 11.5 & 10.5 & 12.5 \\
\hline
\end{tabular}


tracer concentration profiles $1 \mathrm{~km}$ from the release. JU03 wind-tunnel studies (Kastner-Klein et al. 2004) found that the plume shifted erratically by $\pm 45^{\circ}$ around the mean plume axis for release points near the Botanical Gardens site.

There is also a case to be made for the role of stability in explaining the observations. By some measures though, the evidence for this is weak. There were no large diurnal differences in urban boundary-layer stability during JU03, suggesting that stability effects might not have been significant. Stability conditions varied only from very weakly to weakly unstable within the actual CBD depending upon the stability conditions in the approach flow. Vertical profiles of sensible heat flux in the Park Avenue street canyon were measured up to heights of $z / H_{c} \approx 0.3$ and the fluxes were positive for all approach flow stability conditions. (Here $z$ is the measurement height and $H_{c}$ is the canopy height (Ramamurthy et al. 2007)). Sensible heat fluxes ranged up to $0.08 \mathrm{~K} \mathrm{~m} \mathrm{~s}^{-1}$ when the approach flow was unstable, with maximum values found near $z / H_{c} \approx 0.06$, and decreased upward. Sensible heat fluxes for neutral and stable approach flows were also positive but very small. An array of 20 sonic anemometers distributed throughout the CBD with $z=8 \mathrm{~m}$ found that the Obukhov length, $L$, was negative for all IOPs (Hanna et al. 2007), with median values for $L$ yielding $z / L$ of -0.01 and -0.03 for nighttime and daytime IOPs, respectively.

There were also no clear differences in the overall intensities of turbulence between day and night during JU03 (Ramamurthy et al. 2007; Nelson et al. 2007; Klein and Clark 2007). Klein and Clark (2007) and Lundquist and Chan (2007) concluded that the in-canyon flows and turbulence in JU03 were driven primarily by the boundary-layer flow at the level of the average roof height and that stability effects were minor. However, there are some points worth noting. Brown et al. (2004b) and Ramamurthy et al. (2004) reported that wind direction relative to street canyon orientation significantly affected the turbulent features present and how that related to the spatial variability of turbulence (e.g., vortex formation, shear stress). Nelson et al. (2007) found that turbulence intensities in the Park Avenue canyon were greater during south and south-east flows compared to south-west flows. South-east flows were more common during the nighttime IOPs than during the daytime IOPs (Table 1). Nelson et al. (2007); Ramamurthy et al. (2007), and Klein and Clark (2007) all suggested that tall building effects were important in explaining the turbulence observations in the Park Avenue canyon and that these effects were more pronounced in south-east flows. Klein and Clark (2007) found that cross-canyon vortices developed in the Park Avenue canyon during IOPs 8 and 9 but did not during IOPs 4 and 6. Using CFD modelling of the CBD, Chan and Leach (2007) found that the areal extent of stagnation zones was greater, crosswind flow in canyons was weaker, and zones of strong flow reversal were better developed during IOP8 than IOP3. This is consistent with the observed tracer concentration results but is not consistent with the Nelson et al. (2007) finding of greater turbulence intensities in south-east flows.

There is room for uncertainty in interpreting why there are day-night differences in the concentration data. Nevertheless, the results shown in Figs. 2, 3 and 9 suggest that convective mixing likely played a significant role in creating the observed differences. The much smaller normalized concentration footprints and much better vertical mixing are certainly strong evidence for convective mixing and venting of the tracer during the daytime. There is also the greater commonality in the character of tracer concentration time series within IOPs 2-6 and within IOPs 7-10 to consider. These observations are difficult to satisfactorily explain without at least some appeal to the influence of stability and convective mixing. Turbulent bursts associated with convective mixing could have affected the concentration time series and concentration variability in a way analogous to that of wind meander. It might also be conjectured that apparent convective effects on tracer concentrations were being partly expressed through their influence on wind meander. 
These urban plume concentration fluctuation results can also be compared to results from plume studies in open terrain. The general pattern of concentration variability within the JU03 urban plumes is consistent with that observed over homogeneous terrain (Yee et al. 1993, 1994). The greatest concentration variability was found close to the source and near the margins of the plume. Concentration variability decreased towards the plume centreline and downwind as plume spread and internal plume mixing began to replace plume meander as the dominant control on concentration fluctuations away from the source. Although their measurements were only 5-15 m downwind of the source, Mole and Jones (1994) observed much larger daytime concentration variability compared to nighttime. The stability conditions in the CBD during JU03 were similar by day and night. In contrast, the open terrain daytime and nighttime results of Mole and Jones (1994) were obtained in distinctly unstable and stable conditions, respectively.

Yee et al. (1993) measured probability densities during open terrain experiments that were mostly similar in form to those found during JU03. Their open terrain probability densities were characterized by a large peak at zero concentration at receptors close to the source and away from the plume centreline where meander and the plume interface with clean air are important. Further downwind the probability densities were bimodal with peaks at zero concentration and another peak at a non-zero concentration. They attributed the first peak to the effects of plume meander and the second peak was attributed to the in-plume structure. Still further downwind, where the internal plume fluctuations become dominant, the probability densities were unimodal in character with a peak at a non-zero concentration. Yee et al. (1993) also noted a qualitative tendency toward decreased fluctuation intensity at all downwind positions as stability increased. All of these open terrain results are consistent with the observations during JU03.

The magnitude of peak concentrations and their frequency of occurrence in the low probability tail of a probability density are dependent upon sampler response time (or averaging times). The TGA and Miran analysers have slower instrument response times than those in some other studies. Nevertheless, the magnitude of the peak concentrations and their probability of occurrence observed in JU03 are roughly consistent with other studies conducted in more homogeneous flow settings (Sect. 3.3). Some of these studies found clear differences between unconditional and conditional sampling statistics (e.g. Sawford 1987; Mylne and Mason 1991; Yee et al. 1993, 1994). In contrast, the observed probability densities during JU03 for unconditional and conditional sampling exhibit very little difference, expressed as a function of $i$ (Fig. 4), and the concentration fluctuation statistics are mostly in close agreement, with the exception of some modest outliers as intermittency decreases (Figs. 7 and 8).

The results indicate that the magnitude of concentration fluctuations relative to the mean in the heterogeneous JU03 urban environment is similar to that in more homogeneous situations. However, unlike the homogeneous results, there is little difference in conditional and unconditional results. This can be explained by concentration fluctuations being at least somewhat suppressed, in particular, with a reduction in the magnitude of the low fluctuations (i.e., suppression of zeros). Concentrations were less likely to go to zero and at least some tracer was likely to remain during a tracer-flushing event (e.g., wind shift). Concentration fluctuations were still large and often very abrupt but the reduced occurrence of zeros diminished or negated any differences between conditional and unconditional sampling. This suggests that buildings in the CBD trapped or impounded some tracer and acted to reduce the occurrence of zero concentrations relative to a more homogeneous situation. Enhanced mixing due to greater roughness might have also played a role. 
Belcher (2005) also found that an urban canopy acts to reduce concentration fluctuations relative to a homogeneous environment in response to wind direction fluctuations. This is due to the effect of wake zones acting as secondary sources of previously entrained tracer as the plume meanders back and forth.

The case for using simple one-parameter or two-parameter models that rely on more readily available parameters (e.g., $\mu, \sigma_{c}$ ) has been made (Lewellen and Sykes 1986; Yee et al. 1993; Yee and Chan 1997). The finding by Mole and Jones (1994) of no large differences in the shapes of probability density functions in stable and unstable conditions is consistent with the JU03 finding of minimal differences between unconditional and conditional probability densities, and between day and night probability densities, when classified by intensity $i$. These results suggest that if the mean and standard deviation can be determined, whether conditional or unconditional, an estimate of the probability density function for a specified urban location at any time of day can be made. It might then be asked if there is a possible way to apply the results of our study for approximating toxic dosement in emergency situations for a specified location given only an estimate of the mean concentration, toxicity factor $n$ of the pollutant, and an estimate of the relative location of a receptor within an urban plume. It is beyond the scope of the study but, if these were given, it might be possible to develop a model that calculates standard deviation based upon the given mean and information such as that contained in Fig. 6. The dosement could then be calculated using a model dataset based upon selection of a model distribution appropriate to position within the plume, parameterized by the mean and derived standard deviation. Our results might also serve as empirical guidance for model development and validation with respect to concentration fluctuations in urban areas.

\section{Conclusions}

Significant day-night differences in plume dispersion were observed during JU03. Relative to daytime, nighttime plumes were more likely to have suppressed concentration fluctuations (reduced $i$ ), higher normalized surface concentrations, and suppressed vertical mixing. Gaussian-like frequency distributions were more prevalent during the nighttime and log-normal or mixed mode distributions were more prevalent during the daytime. This was in spite of the similar stability conditions in the CBD for day and night. There were only small differences between conditional and unconditional sampling statistics during JU03 relative to the larger differences usually observed in more homogeneous settings. Fluctuation intensity, skewness, and kurtosis are higher for the daytime experiments, and closer to the source, but show little difference between conditional and unconditional results over most of their range of values. Probability densities of concentration are found to be a strong function of intensity $i$. There are few differences in probability densities between day and night when classified by fluctuation intensity. The log-normal distribution provides a better overall fit to a broader range of the dataset than the exponential or clipped-normal distributions.

The analysis demonstrates that knowledge of concentration variability is potentially very significant for urban emergency response planning. Large values of $i$ and $n$ pose a much greater danger than is suggested by the mean concentration taken in isolation.

Acknowledgments We wish to acknowledge the efforts of the many people who contributed to the execution of the JU03 study and made possible the analyses contained in this manuscript. These include Debbie Lacroix, Neil Hukari, Randy Johnson, Shane Beard, Tom Strong, Dianne Hoover, Mark Hoover, David George, Camille Erwin, Sean Eldredge, and Ryan Walker from ARLFRD; Jerry Allwine and Julia Flaherty from the Pacific Northwest National Laboratory; Joe Shinn and Frank Gouveia and support staff from the Lawrence Livermore National Laboratory; Donnie Storwald, Jim Bowers, and support staff from Dugway Proving Ground; Leo 
Stockham of Northrop Grumman; and Shankar Rao and Bruce Hicks for their critique of the manuscript. We also thank the City Engineer Paul Brum and JC Reiss and other staff members of the public works department for the logistical support they provided. This work was supported by the National Oceanic and Atmospheric Administration, by the U.S. Dept. of Homeland Security, and under contract MIPR3ADPG87013 by the Defense Threat Reduction Agency.

Open Access This article is distributed under the terms of the Creative Commons Attribution Noncommercial License which permits any noncommercial use, distribution, and reproduction in any medium, provided the original author(s) and source are credited.

\section{References}

Allwine KJ, Flaherty JE (2006) Joint Urban 2003: study overview and instrument locations. PNNL-15967, Pacific Northwest National Laboratory, Richland, WA, 92 pp

Allwine KJ, Leach M, Stockham L et al (2004) Overview of Joint Urban 2003 - an atmospheric dispersion study in Oklahoma City. 84th AMS Meeting, Paper J7.1, Seattle, WA, January, 2004

Arya SP (1999) Air pollution meteorology and dispersion. Oxford University Press, New York, 310 pp

Belcher SE (2005) Mixing and transport in urban areas. Phil Trans R Soc A 363:2947-2968

Benner RL, Lamb B (1985) A fast response continuous analyzer for halogenated atmospheric tracers. J Atmos Oceanic Technol 2:582-589

Britter RE, Hanna SR (2003) Flow and dispersion in urban areas. Annu Rev Fluid Mech 35:469-496

Brown MJ, Boswell D, Streit G et al (2004a) Joint Urban 2003 street canyon experiment. 84th AMS Meeting, Paper J7.3, Seattle, WA, January, 2004

Brown MJ, Khalsa H, Nelson M et al. (2004b) Street canyon flow patterns in a horizontal plane: measurements from the Joint Urban 2003 field experiment. 5th AMS Urban Environment Conference, Paper 3.1, Vancouver, BC, August, 2004

Burrows DA, Hendricks EA, Diehl SR et al (2007) Modeling turbulent flow in an urban central business district. J Appl Meteorol Clim 46:2147-2164

Chan S, Leach MJ (2007) A validation of FEM3MP with Joint Urban 2003 data. J Appl Meteorol Clim 46:2127-2146

Chatwin PC (1982) The use of statistics in describing and predicting the effects of dispersing gas clouds. J Hazard Mater 6:213-230

Chatwin PC, Sullivan PJ (1993) The structure and magnitude of concentration fluctuations. Boundary-Layer Meteorol 62:269-280

Clawson KL, Carter RG, Lacroix DJ et al (2005) Joint Urban 2003 (JU03) SF 6 atmospheric tracer field tests. NOAA Tech. Memo. OAR ARL-254, Air Resources Laboratory, Idaho Falls, Idaho, 237 pp

Csanady GT (1973) Turbulent diffusion in the environment. D. Reidel Publ. Co., Dordrecht, Holland, 248 pp

EPA (1999) Summary of the U.S. EPA workshop on the relationship between exposure duration and toxicity, United States Environmental Protection Agency, EPA/600/R-99/081, 204 pp

EPA (2004) Revised assessment of detection and quantitation approaches. United States Environmental Protection Agency, EPA-821-B-04-005. Engineering and Analysis Division, Office of Science and Technology, Office of Water (4303T), $286 \mathrm{pp}$

Fairhurst S, Turner RM (1993) Toxicological assessments in relationship to major hazards. J Hazard Mater 33:215-227

Flaherty JE, Lamb B, Allwine KJ et al (2007a) Vertical tracer concentration profiles measured during the Joint Urban 2003 dispersion study. J Appl Meteorol Clim 46:2019-2037

Flaherty JE, Stock D, Lamb B (2007b) Computational fluid dynamic simulations of plume dispersion in urban Oklahoma City. J Appl Meteorol Clim 46:2110-2126

Gryning S-E, Batchvarova E, Rotach MW et al (2005) Roof-level SF6 tracer experiments in the city of Basel. Zurcher Klima-Schriften 85:83

Hanna SR (1984) Concentration fluctuations in a smoke plume. Atmos Environ 18:1091-1106

Hanna SR, Britter R, Franzese P (2003) A baseline urban dispersion model evaluated with Salt Lake City and Los Angeles tracer data. Atmos Environ 37:5069-5082

Hanna SR, White J, Zhou Y (2007) Observed winds, turbulence, and dispersion in built-up downtown areas of Oklahoma City and Manhattan. Boundary-Layer Meteorol 125:441-468

Hendricks EA, Diehl SR, Burrows DA et al (2007) Evaluation of a fast-running urban dispersion modeling system using Joint Urban 2003 field data. J Appl Meteorol Clim 46:2165-2179 
Kastner-Klein P, Leitl B, Pascheke F et al (2004) Wind-tunnel simulation of the Joint Urban 2003 tracer experiment. 84th AMS Meeting, Paper 5.4, Seattle, WA, January, 2004

Klein P, Clark JV (2007) Flow variability in a North American downtown street canyon. J Appl Meteorol Clim 46:851-877

Kodavanti UP, Costa DL, Giri SN et al (1997) Pulmonary structural and extracellular matrix alterations in Fischer 344 rats following subchronic phosgene exposure. Fundam Appl Toxicol 37:54-63

Lewellen WS, Sykes RI (1986) Analysis of concentration fluctuations from lidar observations of atmospheric plumes. J Clim Appl Meteorol 25:1145-1154

Lundquist JK, Chan ST (2007) Consequences of urban stability conditions for computational fluid dynamics simulations of urban dispersion. J Appl Meteorol Clim 46:1080-1097

Miller FJ, Schlosser PM, Janszen DB (2000) Haber's rule: a special case in a family of curves relating concentration and duration of exposure to a fixed level of response for a given endpoint. Toxicology 149:21-34

Mole N, Jones CD (1994) Concentration fluctuation data from dispersion experiments carried out in stable and unstable conditions. Boundary-Layer Meteorol 67:41-74

Mylne K, Mason PJ (1991) Concentration fluctuation measurements in a dispersing plume at a range of up to 1000 m. Q J Roy Meteorol Soc 117:177-206

Nelson MA, Pardyjak ER, Klewicki JC et al (2007) Properties of the wind field within the Oklahoma City Park Avenue street canyon. Part I: Mean flow and turbulence statistics. J Appl Meteorol Clim 46:2038-2054

Peterson H, Lamb B (1992) Comparison of results from a meandering-plume model with measured atmospheric tracer concentration fluctuations. J Appl Meteorol 31:553-564

Peterson H, Lamb B (1995) An investigation of instantaneous diffusion and concentration fluctuations. J Appl Meteorol 34:2724-2746

Ramamurthy R, Pol S, Pardyjak E et al (2004) Spatial and temporal variability of turbulent fluxes in the Joint Urban 2003 street canyon. 5th AMS Urban Environment Conference, Paper 3.4, Vancouver, BC, August, 2004

Ramamurthy P, Pardyjak ER, Klewicki JC (2007) Observations of the effects of atmospheric stability on turbulence statistics deep within an urban street canyon. J Appl Meteorol Clim 46:2074-2085

Ride DJ (1984) An assessment of the effects of fluctuations on the severity of poisoning by toxic vapours. J Hazard Mater 9:235-240

Sawford BL (1987) Conditional concentration statistics for surface plumes in the atmospheric boundary layer. Boundary-Layer Meteorol 3:209-223

Sykes RI, Henn DS (1992) Large-eddy simulation of concentration fluctuations in a dispersing plume. Atmos Environ 26A:3127-3144

ten Berge WF, Zwart A, Appelman LM (1986) Concentration-time mortality response relationship of irritant and systematically acting vapours and gases. J Hazard Mater 13:301-309

Venkatram A, Isakov V, Pankratz D et al (2005) Relating plume spread to meteorology in urban areas. Atmos Environ 39:371-380

Witschi H (1999) Some notes on the history of Haber's Law. Toxicol Sci 50:164-168

Yee E, Chan R (1997) A simple model for the probability density function of concentration fluctuations in atmospheric plumes. Atmos Environ 31:991-1002

Yee E, Kosteniuk PR, Chandler GM et al (1993) Statistical characteristics of concentration fluctuations in dispersing plumes in the atmospheric surface layer. Boundary-Layer Meteorol 65:69-109

Yee E, Chan R, Kosteniuk PR et al (1994) Experimental measurements of concentration fluctuations and scales in a dispersing plume in the atmospheric surface layer obtained using a very fast response concentration detector. J Appl Meteorol 33:996-1016 